\title{
Analysis on the Status Quo and Prospect of Interconnection between Traffic Areas in the Bangladesh-China-India-Myanmar Economic Corridor
}

\author{
Hongmei Li \\ International Business School \\ Yunnan University ofFinance and Economics \\ Kunming, China \\ 1198325349@qq.com \\ Chunjin Duan* \\ International Business School \\ Yunnan University ofFinance and Economics
}

\author{
Kunming, China \\ 530717867@qq.com
}

Wenbo Du

International Business School

Yunnan University ofFinance and Economics

Kunming, China

122894558@qq.com

\begin{abstract}
The interconnection in the field of transportation is a key factor in the breakthrough development of the Bangladesh - China - India -Myanmar Economic Corridor and is also the guarantee for the integration of energy, agriculture, industry, and telecommunications in the four countries of Bangladesh, China, India and Myanmar. the basis of interconnection Bangladesh China - India - Myanmar Economic Corridor, this paper analyzes the current situation of traffic distribution, and the difficulties of hardware facilities, traffic management systems, and financing, Analyze the economic effects brought by the interconnection of the transportation areas, and puts forward the path choice to promote the Bangladesh - China - India - Myanmar Economic Corridor in the future. The realization of transportation interconnection between the four countries of the Bangladesh, China, India and Myanmar will promote the implementation of the strategy Bangladesh-China-India-Myanmar Economic Corridor, accelerate the pace of the construction of the economic corridor between Bangladesh, China, India and Myanmar, and serve as a good model for the interconnection of other areas.
\end{abstract}

Keywords-Bangladesh-China-India-Myanmar; corridor; traffic; interconnection introduction

\section{INTRODUCTION}

In May 2013, during Prime Minister Li Keqiang's visit to India, China and India jointly proposed the construction of the Bangladesh -China - India - Myanmar Economic Corridor, and jointly announced the establishment of a joint working group, which enabled the two major markets of China and India to be closely linked and strengthen the interconnection of the region. Bangladesh - China - India - Myanmar Economic Corridor passes through southwest China, north and northeastern Bangladesh, northern India and northern Myanmar. Take the 4 cities of Kunming, Calcutta, Dhaka and Mandalay as the main nodes, through the construction of the infrastructures along

*Corresponding author highways, railways, electricity, and communications, the crossregional economic cooperation zone, establish an advantageous industrial park, border crossing system, and features along the route tourism lines and so on, to achieve interconnection and complementary advantages in the region, and common economic development [1].

\section{TRAFFiC Situation ANALYSIS}

At the present stage, there are many obstacles to the cooperation and construction of the traffic channels between Bangladesh, China, India and Myanmar. The reasons are as follows: First, the four countries ignored the Convention on Transnational Land Transport Facilitation, which seriously hindered the cultural exchange and logistics transportation between Bangladesh, China, India and Myanmar. and on June 11, 2009, in order to promote and develop international rail transport in Asia and its surrounding regions, members of the United Nations Asia-Pacific Economic Cooperation Joint Committee signed the "Trans-Asian Railway Network." Intergovernmental agreement, this land transport convention currently only China and India to join.

Second, the transport agreement in the border area of the Bangladesh-China-India-Myanmar Economic Corridor has numerous complicated restrictions on the transit of people, goods, and vehicles. It is not conducive to economic, trade and industrial cooperation. This is closely related to the consideration of national security in various countries. For example, India hopes to build a channel to strengthen ties with the eastern states of India. However, this channel needs to cross Bangladesh, and Bangladesh has been worried the completion of the passage will threaten national security. So it has not agreed to India to open up this passage. Since the 1970s, separatist political and armed struggles in the northeastern 
Indian region have not ceased. At present, there are more than 120 anti - government organizations of different sizes in the northeastern part of India and more than 50 with frequent armed activities. Therefore, the Indian government is extremely worried that after the construction of the passage, it will become a channel for terrorists' outreach activities. Burma's political and economic openness is not high, and domestic antigovernment armed activities frequently occur, which has great concern for improving the transportation infrastructure in the border areas [2]. Third, it is difficult to meet the shortage of construction funds. Currently, the highways, railways and waterways of the four countries of Bangladesh, India, and Myanmar are independent of each other. Each system is formed. The construction standards are not uniform and there are great differences.

There are also missing road sections and border transportation management facilities are backward along the economic corridor. In order to achieve a convenient transportation network of the Bangladesh - China - India Myanmar Economic Corridor needs planning, rectification, and reconstruction of many sections of roads with large capital requirements [3]. As the underdeveloped countries in Bangladesh and Myanmar, the level of economic development is not high, so the shortage of funds in the construction of transport infrastructure is very serious. How to solve the financial difficulties is a problem that needs to be solved urgently.

There are three routes planned for the road direction of the Bangladesh-China-Indian -Myanmar Economic Corridor. The first southern route project starts from Kunming, China, passes through Dali, Baoshan, and Ruili, then passes through Myanmar, Laechen, to Mandalay, and continues southwestwards until it drifts through Chittagong, Bangladesh and Dhaka, and finally arrives in Calcutta, India. The second midline scheme is from Kunming to Ruili in China, and then to Mandalay, Myanmar, to the northwest, to the Demu Port in Myanmar, and to Dhaka in Bangladesh by India, and finally to Calcutta in India. The third is the North Line program, from Kunming, China to Baoshan Tengchong.

After leaving the country to Myitkyina in Myanmar, and then to India via Redo and Imper to Dhaka, Bangladesh, and finally to Calcutta, India. In terms of line selection, each country has its own focus. Myanmar and Bangladesh hope to implement the midline, while China prefers the south line, while India wants to advance the northern line. These differences have increased the difficulty and uncertainty of the international coordination of economic corridor construction. Judging from the current situation, it is necessary for all governments to do a good job of increasing trust and clearing suspicions, consider the interests of all parties as a whole, determine the priority lines and projects, and solve a series of problems such as the connection of capital and technology so that they can be implemented in a coordinated manner.

\section{PROSPECTS ANALYSIS}

The roads and railways of the Bangladesh-China-IndiaMyanmar Economic Corridor have not yet formed a complete network and the standards of countries in the railroad track are different. In Bangladesh and Myanmar, the road networktechnology and access is poor, and interconnection is the basis for the promotion of regional economic integration and the construction of the Bangladesh - China - India Myanmar economic corridor it is therefore necessary to place interconnection as a key direction for the construction of the economic corridor and should be placed in the priority development position. Combining the needs of current economic and trade cooperation and the direction of future development, comprehensively consider the division of labor and cooperation of various countries, conduct connectivity and improvement on the basis of existing transportation, establish a transportation network, and enhance the ability to reach each other between regions, so that China can achieve The comprehensive transportation system for roads, railways, waterways, and aviation with neighboring countries.

The planning for interconnection of the Bangladesh-ChinaIndia-Myanmar Economic Corridor in the areas of transportation should achieve interconnection with other countries, enhance mutual cooperation, and avoid competition. First, the four countries did not sign an agreement on land transport facilitation. But, they can make full use of the existing "Asian Highway Network Intergovernmental Agreement" and "Intergovernmental Agreement on the Trans - Asian Railway Network" and other international transportation development plans. All Countries should conscientiously implement land transportation facilities. To reduce the construction resistance and speed up the realization of highways and railways within the economic corridor. The second is to strengthen the communication and coordination between Bangladesh, China, India and Myanmar, formulate a overall strategic plan, clarify the key and priority areas for interconnection, and try to achieve convergence with national economic development planning and transportation route planning. The third is to prioritize the upgrading of the existing routes of Bangladesh, China, India and Myanmar, speed up the construction of missing road sections, and further improve the aviation lines between the four countries. Fourthly, the planning of the land routes of Bangladesh, China, India, and Myanmar should be based on the principle of connecting the central cities and main cities along the economic corridor. Currently, it can refer to the planned routes of the Asian Highway Network and the Trans-Asian Railway Network. According to China's Yunnan, Bangladesh, India, Myanmar's existing land, sea and air infrastructure, the construction of Bangladesh-China-India-Myanmar traffic corridor.

\section{A. Highway}

Highway traffic corridors can give priority to linking missing road sections and upgrade existing road grades. The middle line, which is the planned route for the Asian Highway Network, and the "Kunming-Mandalay-Inghal-DhakaKalkata" road routes link the four countries of Bangladesh, China India, and Myanmar; In 2012 and 2013, we completed 1 road tests and one auto set-up match, and entered India two times. We still need to upgrade highway grades. The south line, the southbound route of the Asian Highway Network, and the "Kunming-Mandalay-Chittagong-Daka-Kalkata" section, connecting the central cities of the countries along the route, 
need to link the missing sections of the Myanmar-Mengau border. In addition, the Northern Line can also link the road between India-Myanmar and China-Myanmar, the historic Stilwell Road was opened. In Myanmar, bridges need to be built, and some mountain roads need to be built according to highway grades.

1) China-Myanmar border can focus on promoting the following cross-border highway construction

The first is the Ruili-Mujie Line, which is now the tar road and coincides with the Pan-Asian Line 14 (AH14); The second is the Tengchong Monkey Bridge - Myitkyina Line. Tengchong-Myitkyina Secondary Highways are connected to Myanmar Highway 31 via the Monkey Bridge Port. The third is the Qingshuihe- Dala Line, which passes through the Qingshuihe Port of Meng Ding, connects with Myanmar's No. 34 and No. 3 highways to connect Dala and Mandalay, focusing on upgrading the road grade; The fourth is the Jinghong-Daluo Port-Jingdong (Myanmar) line, which coincides with the Pan-Asian Highway Line 3 (AH3); The fifth is Zhangfeng- Myanmar Bamo Line, focusing on the upgrading of road grades; Sixth, Yingjiang Nabang-La Gyar Yang (Myanmar) Line, exiting through Yingjiang Port, mainly for assistance; Seventh is the Menglian- Myanmar line, which is a rural road in Myanmar and will be upgraded in the future. In terms of construction timing, the construction of high-grade cross-border highways in Tengchong Monkey BridgeMyitkyina-Port in Mengding, Dala ,Daluo Port and Jingdong should be promoted in the near term; the medium-term promotion of Zhangfeng-Bamogang Highway and SimaoMenglian Port t highway will be upgraded; Gongshan-MakuPutao Highway will be advanced in the future [5].

2) The border between India and Myanmar can promote three cross-border highways

The India-Myanmar border can promote three cross-border highways, the Mude-Morley line, which enters Manipur via the Indian border Morey. This road coincides with the Pan-Asian highways (AH1, AH2), and is the China-India-Myanmar international channel middle line; The second is the Myitkyina-Raydo line, which is the northern line of ChinaIndia-Myanmar international route; The third one is the Giling Temple (Myanmar)-Zokhawthar (India) line. It enters India via the Giling Temple and Zokhawthar. In terms of construction timing, the construction of the Mandalay-Mud-Morey-Ingbar highway should be focused on in the near future, and the technical grade of the Myitkina- Raydo highway should be gradually increased in the long term. The border between Myanmar and Bangladesh has no direct access to the highway and can only enter India via the road to Chittagong, Bangladesh. It plans to construct the Mandalay-MaguigChittagong Expressway Railway to form the South Line of Bangladesh -China-India-Myanmar, connecting to Pan-Asian Highway 41 (AH41).

\section{B. Railway}

1) The Cross- Border Railway in China -Myanmar can consider the west line of the Pan Asian Railway

The planning route of the India -Myanmar railway is basically consistent with the Asian Highway Network (middle line). The direction of the China -Myanmar railway planning is roughly the same as the India- Myanmar railway, which can form a docking. In 2011, China and Myanmar signed the "Memorandum of Understanding for the Mou - Kyaukpyu Railway Construction Project Cooperation" and supplementary agreement, which stipulated that the project construction must start within three years from the date of signing. The project is planned to invest 20 billion dollars, and it will be completed by 2015. China is responsible for raising most of the funds and has 50 years of operation rights. The planned railway is basically parallel to the China -Myanmar oil and gas pipeline. However,due to Myanmar's domestic opposition to the project, after the expiry of the 2014 memorandum of understanding, both China and Myanmar stated that they will suspend the project. Although the Mujie- Kyaukpyu Railway has not been construction as scheduled, in China, the Kunming-Dali section has been opened, and the Dali-Ruili section is under construction. The construction of the railway is still advancing steadily. In the long run, the single-line internal-combustion track railway from Mandalay to Kyaukpyu will be an important channel and supporting infrastructure for the development of the Bangladesh-China-Indian -Myanmar Economic Corridor. China should maintain consultations with Myanmar and take the opportunity to promote China-Myanmar international railways. In addition, Sino-Myanmar cross-border railways can also focus on the construction of the JinghongBohai-Daluo-Jingdong-NanSang cross-border railway and the Baoshan-Monkeybridge-Myitkyina cross-border railway as an early construction project of the China-Indian Railway. Promoted the preliminary research work of the railway from Tengchong Monkey Bridge border from Myitkyina in Myanmar to the Bansao Port on the Indian border.

\section{2) India-Myanmar cross-border}

India-Myanmar cross-border railway is still in planning coordination. At present, we can focus on promoting the construction of cross-border railways between Myanmar-India. The construction of a cross-border railway in Myitkyina Raido will be constructed in the near future, and the construction of the Jirbam(India) Cross-Border Railway in India will be constructed in the future.

3) India-Mongolia Cross-border Railway

India is connected to the state-owned cross-border railway in Bangladesh. Calcutta-Dhaka Railway passenger transportation service began during the British colonial rule. In 1965, India and Pakistan broke out the second war due to the Kashmir issue. As a result, the railway traffic between India and Pakistan was interrupted, and Bangladesh was part of Pakistan. In January 1972, Bangladesh was formally established, but the railway passenger services in India and Bangladesh have not been restored. It was not until 2008 that India -Bangladesh resumed rail passenger transport. The "India-Bangladesh Friendship Train" runs twice a week. The railway is 538 kilometers long and takes 13 to 14 hours. On the one hand,there are two railways in Assam, northeastern India, connected to Chittagong, Bangladesh, and Dhaka. On the other hand, the border between Bangladesh and Myanmar is on the Bay of Bengal and there is no cross-border railway connection. It will promote the construction of the cross-border railway in 
Magway（Myanmar)-Chittagong (Bangladesh) in the long

\section{Aviation}

Due to the backward transportation infrastructure and long construction period in Bangladesh-China-Indian-Myanmar, international aviation cooperation is the key to strengthening multilateral cooperation and enhancing business and cultural exchanges. Bangladesh-China-Indian -Myanmar Economic Corridor should form an international aviation network as soon as possible. In particular, the construction of Kunming Changshui International Airport should be strengthened to take advantage of its advantageous geographical location in Southeast Asia and South Asia, and actively seek to open up the fifth freedom rights, to launch the domestic segment transit connection service of international flights, and to match the flight schedules of domestic and foreign routes, Kunming The airport is built into the hub of China, and even Northeast Asia, to transfer Southeast Asia to South Asia and the Middle East. At the same time, the focus will be Mangshi, Jinghong, Simao Airport transformed into an international airport. The Mid-term will continue to promote the construction of Myitkyina, Ba Mo, and Handan Floating Port as international airports serving the Bangladesh-China-Indian -Myanmar Economic Corridor, and increase the international routes between Bangladesh-ChinaIndian -Myanmar to further improve the aviation network.

\section{SUMMARY}

The construction of the transport interconnection of the Bangladesh-China-Indian -Myanmar Economic Corridor is a long-term and complex system project involving both domestic and foreign countries. It is necessary to effectively increase support at the national level, strengthen route planning and term.

high-level promotion, and also require the relevant domestic provinces and regions, especially Yunnan Province, to actively play the frontier and the main role. Based on the current, focusing on the long-term, internal and external linkage, and actively promote the interconnection of the transport sector; Early harvesting, key projects as the starting point, exploration of the path and measures to promote the construction of transportation infrastructure, gradual and orderly progress, difficulty in the first place, and significant progress in promoting the interconnection of the Bangladesh-China-Indian -Myanmar Economic Corridor.

\section{REFERENCES}

[1] Lijun Chen, The Bangladesh-China-India-Myanmar Economic Corridor and the Construction of the "Belt and Road", South Asia, South Asia Study, 2015.

[2] Xin Li, An Analysis of the Interconnection between India and Myanmar, South Asian Studies,"2014.

[3] Tosten Hagerstrand, Innovation as a Spatial Process, Chicago University of Press, 1967.

[4] Douglass C. North, Institutions, Institutional Change and Economic Performance, Cambridge: Cambridge University Press, 1990.

[5] Tao Xie and Qing Chang,China Railways Co Ltd. Constructs the "Great Overseas Strategy of the Sino-Burmese Railway. Securities Daily, 2011.

[6] The construction of the first phase of the construction of the Ganjiang River's fifth-grade channel is completed. The 300 - ton ship can pass all the year round. China Water Transport, http://www.zgsyb.com/GB/Article/ShowArticle.asp? ArticleID=6737.

[7] Build "Bridgehead" Traffic Pioneers - Visit Provincial Department of Transportation, http://www.ynjtt.com/Item.aspx? Id=1112. 